\title{
Juventude, escola e trabalho: permanência e abandono na educação profissional técnica de nível médio
}

Monica Ribeiro da Silva'

Lucas Barbosa Pelissarill

Allan Andrei Steimbach"II

\section{Resumo}

0 artigo aborda a temática das relações entre juventude e escolarização, propondo-se a discutir as razões de permanência e abandono no âmbito da educação profıssional técnica de nível médio. Inicialmente, apresenta uma discussão conceitual sobre juventude, escola e trabalho para, em seguida, expor os resultados de duas pesquisas empíricas que se ocuparam de analisar o que levam os jovens a abandonar ou a permanecer na escola. Os dois cursos investigados foram definidos por possuírem, ambos, elevada procura, sendo que em um deles há alto índice de abandono, ao passo que o outro apresenta uma permanência acima da média se comparada a outras escolas de ensino médio. A análise sinaliza que a grande procura pelos cursos técnicos nas áreas pesquisadas deve-se ao fato de os jovens buscarem encontrar formação de qualidade superior, profissionalização em áreas que representam certo status ou, ainda, garantia de empregabilidade. Em uma das situações, ao se frequentar a escola, as ilusões iniciais dissolvem-se, problemas para acompanhar a realização do curso evidenciam-se e a relação entre a escola e o jovem mantém-se distante, o que leva ao abandono. Contrariamente, em outra situação, a permanência é explicada devido ao grau de experiências positivas que os jovens podem viver enquanto estão matriculados em uma instituição de tempo integral, interna e bem estruturada.

\section{Palavras-chave}

Juventude e educação - Permanência e abandono escolar - Ensino médio - Educação profissional técnica de nível médio.

I- Universidade Federal do Paraná, Curitiba, PR, Brasil. 


\title{
Youth, school and work: attendance and dropout in technical professional secondary education
}

Monica Ribeiro da Silva'

Lucas Barbosa Pelissarill

Allan Andrei Steimbach"II

I- Universidade Federal do Paraná, Curitiba,

PR, Brazil.

Contact:monicars@ufpr.br

II- Universidade do Oeste do Paraná, Foz do lguaçú, PR, Brazil

Contact: lucasbpelissari@hotmail.com

III- Colégio Estadual Mário de Andrade,

Francisco Beltrão, PR, Brazil.

Contact:a-andrei@hotmail.com

\begin{abstract}
The article deals with the theme of the relations between youth and schooling, proposing a discussion of the reasons for the attendance and dropout within the technical professional secondary education. Initially, it presents a conceptual discussion about youth, school and work, and then it puts forward the results of two empirical researches that analyzed the reasons why youngsters drop out from, or remain at, the school. The two courses investigated were chosen because they were both in high demand, with one of them displaying a high level of dropout, whereas the other presents a rate of attendance above the average of other secondary schools. The analysis signals to the fact that the reasons for the high demand for technical courses in the areas investigated here are that youngsters look for high quality education, seek professionalization in areas that are associated with high status and, still, that they aim at guaranteed employability. In one of these situations, when attending school the initial illusions vanish, problems to keep up with the course appear, and the relation between the school and the youngsters remains distant, bringing with it the dropout. In the other situation, attendance is explained by the degree of positive experiences that youngsters have while they are enrolled in a full-time, well structured, boarding school.
\end{abstract}

\section{Keywords}

Youth and education - School attendance and school dropout Secondary education - Technical professional secondary education. 
As investigações a respeito dos fatores que se relacionam com o abandono e a permanência dos jovens na escola, sobretudo no ensino médio regular e na educação profissional técnica de nível médio, têm importância significativa para a compreensão da dinâmica social desse segmento da população brasileira - a juventude. Mas qual é a relevância desse assunto no que diz respeito ao entendimento das condições de vida, de trabalho e de escolaridade dos jovens? As múltiplas contradições verificadas nas tensões entre o contexto escolar e a dinâmica da juventude impõem problematizações importantes: Quais são os motivos que têm levado os jovens a abandonar a escola? 0 que os levaria a permanecer? Os sentidos e significados atribuídos à escola constituem-se em fatores que explicam o que os leva a abandonar ou a permanecer na escola? Por que muitos jovens continuam indo à escola, ainda que tenham abandonado o sentido propriamente escolar dessa instituição? E o que dizer dos que insistem em frequentar a escola, ainda que estejam abandonados dentro dela?

Procurando justificar a importância do tema que abordamos neste texto, tentamos responder a essas perguntas expondo, inicialmente, um duplo movimento que temos constatado na dinâmica da cultura escolar no Brasil, especificamente no que se refere à última etapa da educação básica. 0 primeiro elemento desse duplo movimento diz respeito aos índices de abandono escolar; o segundo, a um fenômeno denominado esvaziamento de significado do espaço escolar (COSTA; KOSLINSKI, 2006) ou, ainda, desaparecimento da instituição escolar (DUBET, 1997).

Assim como a própria categoria juventude e as transformações mais gerais que afetam a sociedade como um todo, também a visão de escola elaborada pelos jovens tem sofrido metamorfoses, de modo que o espaço escolar (ou a instituição escolar) passa por um processo de ressignificação.

0 ensino médio, em que pese a importante condição de ser considerado parte da educação básica, padece de um quadro acentuado de exclusão. A taxa média de abandono e reprovação é de 35,5\%, verificada entre os anos de 2007 e 2009 (BRASIL, 2009). Apenas $48 \%$ dos matriculados estão na faixa etária considerada regular, isto é, possuem entre 15 e 17 anos. Mais de 40\% das matrículas ocorrem no período noturno.

No caso específico da educação profissional técnica de nível médio, apesar do significativo aumento na oferta de vagas ocorrido nos últimos anos, ${ }^{1}$ tem-se constatado um panorama de expressivo abandono. Há casos em que a taxa de abandono passa de 75\% (BRASIL, 2009), número não raro quando se trata da modalidade PROEJA ou de qualquer modalidade ofertada no período noturno. ${ }^{2}$ Essas constatações não se restringem aos dados obtidos na pesquisa mencionada, mas são também verificadas em outras análises a respeito do ensino médio no Brasil (ABRAMOVAY, 2003; DAYRELL, 2009).

Por outro lado, esses primeiros elementos que até aqui apresentamos - o alto abandono escolar e o esvaziamento de sentido da escola - são

aparentemente contraditos pelo afluxo crescente de candidatos ao alistamento escolar, bem como pela indiscutivel relevância que a educação escolar desfruta entre os discursos que alcançam repercussão pública. (COSTA; KOSLINSKI, 2006, p. 133)

Ou seja, verifica-se - ao mesmo tempo em que se percebem altas taxas de abandono - a ênfase na importância da escola para a vida do jovem, de maneira que juventude e escolaridade passam, em alguns momentos, a confundir-se, dada a organicidade dessas duas condições de vida na modernidade. Em face dessa contradição,

1- Os últimos dados do Censo Educacional mostram que, em 2009, 0 número de matrículas nessa modalidade de ensino foi de 1.036.945, configurando uma expansão de quase 80\% entre 2003 e 2009 (INEP, 2009). 2 - Há exceções nessa realidade de abandono escolar, como se pode verificar numa das pesquisas relatadas neste artigo. Foi justamente esse o motivo que levou ao estudo do Curso Técnico em Agropecuária Integrado dos Colégios Agrícolas do Estado do Paraná. 
cabe questionar, por exemplo, se estaria de fato havendo um esvaziamento de sentido da escola ou se não seria melhor reportarmo-nos a um deslocamento de significado do processo de escolarização em direção às questões postas pelo universo juvenil na atualidade.

De qualquer forma, apresenta-se a urgente necessidade de, articulando-se às análises com foco nas instituições e nas determinações econômicas, centrar as pesquisas atuais a respeito da escola de nível médio nos sujeitos e verdadeiros atores desse processo: os jovens que o frequentam.

\section{Juventude(s), escola, trabalho}

Vistas as questões gerais que nos levam a compreender os sujeitos jovens como centrais para um processo mais amplo de (re)construção e reflexão a respeito das políticas públicas para o ensino médio no Brasil, entendemos como necessário que se delimite sociologicamente a categoria juventude e, mais do que isso, que se discuta de maneira aprofundada como se dão os processos de construção identitária do jovem na sociedade atual.

A fim de esclarecer as relações entre os sentidos e significados que os jovens atribuem à escola e o panorama de abandono que temos verificado, faz-se necessário analisar as imbricações entre os processos de construção identitária, a cultura escolar, a sociedade de modo geral e o mundo do trabalho em particular, à luz das contradições e dos movimentos que a realidade contemporânea impõe.

Quando tratamos de concepções sociológicas a respeito de determinadas categorias, é importante termos em mente que tais concepções não são estáticas. Ao contrário, são sempre suscetíveis a novos olhares e aportes. É nesse sentido que entendemos que o recorte etário para a categoria juventude, até então utilizado recorrentemente por pesquisadores das mais diversas vertentes teóricas, possui - sobretudo na sociedade do pós-guerra, que trouxe consigo profundas remodelagens na estrutura econômica capitalista e, consequentemente, no mundo do trabalho - sérios limites. Da mesma forma, as abordagens funcionalistas, de matriz positivista e iluminista, que imputam à juventude uma natural predisposição à transgressão e à delinquência são absolutamente inadequadas para qualquer análise social que se procure fazer.

Dessa maneira, opondo-se a essas duas abordagens, partimos do pressuposto de que a juventude é uma categoria que não tem sentido se não analisada como uma construção histórica e social, permeada por todas as lutas e contradições que movem a sociedade. É isso o que leva Bourdieu (1983) a afirmar que

a idade é um dado biológico socialmente manipulado e manipulável; e que o fato de falar dos jovens como se fossem uma unidade social, um grupo constituído, dotado de interesses comuns, e relacionar estes interesses a uma idade defınida biologicamente já constitui uma manipulação evidente. (p. 2)

0 autor nos mostra que a fronteira entre a juventude e a velhice, por exemplo, é um objeto de disputa em todas as sociedades, de modo que tais categorias não são dadas, mas construídas socialmente na própria luta entre jovens e velhos. Dessa forma, as relações entre as idades social e biológica são bastante complexas.

Dayrell (2003), sustentando-se nessa mesma concepção histórico-social, também apresenta uma importante crítica às análises que tomam, etária e biologicamente, a juventude como uma fase de transitoriedade entre a infância e a vida adulta. Para o autor, essa proposta é uma negação do presente vivido pelo jovem como espaço-tempo de formação, pois, segundo ele, a juventude, como categoria definida histórica e socialmente, não possui caráter universal, homogêneo ou estável.

Há que se analisar, pois, a diversidade de fatores e as condições sociais em que emerge a condição juvenil na atualidade. Um desses fatores diz respeito às mudanças ocorridas na sociedade a partir das transformações no mundo do trabalho. 
Tal aspecto é considerado relevante na análise do ensino médio, visto que se identifica como uma das preocupações presentes no universo juvenil, em especial por parte daqueles que se encontram na última etapa da educação básica: a questão da profissionalização e do emprego.

As mudanças ocorridas nos processos de produção e de trabalho com a aplicação de novas tecnologias e o aparecimento das novas formas de gestão geraram significativas metamorfoses na vida social, fazendo com que a inserção no mercado de trabalho e a própria qualidade do processo laboral passassem a ser bastante diferentes do que era verificado até então. Essas transformações não se restringem às esferas econômica e produtiva, mas a todas as relações sociais, massificando ainda mais o controle e a administração da vida humana e a mercantilização da vida social.

Harvey (2010) demonstra que a acumulação flexível implica níveis relativamente altos de desemprego estrutural, rápida destruição e reconstrução de habilidades, ganhos modestos de salários reais e retrocesso do poder sindical. Nesse intenso movimento de reestruturação, emergem também novas exigências laborais e reforça-se a ideologia segundo a qual cabe ao indivíduo, e não à estrutura econômico-social, ser empregável, rompendo com a ideia de qualificação como um atributo construído social e historicamente. Nesse contexto, por meio de orientações presentes nas políticas curriculares, os processos de educação formal passam a receber a tarefa de desenvolver nos sujeitos as novas competências requeridas, representando uma convergência entre educação e emprego e uma adaptação da escola à sociedade, mesmo que esta se organize de forma excludente e discriminatória (SILVA, 2008).

Como o jovem situa-se no centro dessas transformações, não só do ponto de vista econômico, mas também de uma perspectiva cultural e subjetiva, investigar seus impactos na vida juvenil, sobretudo nos processos de formação escolar e profissional, pode trazer maior solidez para análises sobre a juventude contemporânea. Para
Sposito (2008), são precisamente essas transformações que não permitem mais que se fale em completa autonomia quando se faz referência à situação do adulto na sociedade. Ou seja, a crise da sociedade assalariada, construída no âmago dessas mudanças no mundo do trabalho - e principalmente da imposição do desemprego como categoria de natureza estrutural e permanente para grandes contingentes populacionais -, cria as condições para que a autonomia do adulto por meio da independência financeira possa não se realizar. Com enormes segmentos excluídos da possibilidade de trabalho, é indispensável buscar outros elementos definidores da condição adulta, para além da independência financeira. Portanto, a condição singular da juventude de fase da vida em que se busca tal autonomia, rompendo com a heteronomia infantil, torna-se muito mais complexa.

Com isso, queremos mostrar que a diversidade de fatores que sempre definiram a entrada de qualquer indivíduo na vida adulta é ainda mais acentuada na sociedade atual. Ao jovem resta a imensa dificuldade de encontrar uma inserção decente no mundo do trabalho ou até de encontrar trabalho, configurando aquilo que Abramo (2008) denominou extensão da juventude, processo marcado, por exemplo, pelo prolongamento do tempo destinado à formação escolar e pela maior dependência financeira em relação à família. A mesma autora nos chama atenção para o fato de ser necessário recorrer à categoria juventudes, no plural, para que se tenham sempre claras as desigualdades e diferenças que a atravessam.

Agora a pergunta é menos sobre a possibilidade ou impossibilidade de viver a juventude, e mais sobre os diferentes modos como tal condição pode ser vivida. (ABRAMO, 2008, p. 43-44)

Alguns dados que resultam desse contexto de reconfiguração do mundo do trabalho, notadamente entre indivíduos cuja idade é compreendida entre os 15 e os 29 anos, dão-nos 
uma ideia dessa heterogeneidade de condições de vida e, principalmente, das tensões vividas pela juventude ao (tentar) adentrar o mundo do trabalho. Pochmann (2007) mostra que, entre 1995 e 2005, o Brasil gerou 17,5 milhões de novas ocupações, dentre as quais apenas 1,8 milhões foram preenchidas por pessoas entre 15 e 24 anos de idade; porém, quase 4,2 milhões de jovens entraram no mercado de trabalho nesse período. Analisando o período posterior a esse, o autor constata, ainda, que a taxa de desocupação juvenil no Brasil, em 2006, foi de 14,8\%, com um aumento para 16,6\% em 2009 (IBGE, 2010). Entre pessoas com mais de 30 anos de idade, essa taxa não passou dos 5,2\% nesse período (POCHMANN, 2007; IBGE, 2010).

Também é importante ressaltar a qualidade dos postos de trabalho gerados e, principalmente, aqueles ocupados pela população pobre. No Brasil, por exemplo, como mostra Simões (2010), cerca de 4 milhões de jovens trabalham em atividades informais, das quais 90\% correspondem a menos de um salário mínimo.

Entretanto, mesmo com a ênfase na importância da busca por educação formal, percebemos não só a não ocorrência de uma relação linear entre educação e empregabilidade, como também, em alguns casos, a inversão desse processo: taxas mais altas de desocupação ou desemprego correspondem a grupos juvenis mais escolarizados. Importante estudo realizado por Ribeiro e Neder (2009), por exemplo, mostra que, ao contrário do que se espera pelo senso comum e do que propala a teoria do capital humano, para algumas faixas etárias e alguns estratos econômicos no Brasil, as taxas de desocupação correlacionam-se positivamente com os anos de estudo. Ou seja, taxas menores de desocupação são encontradas para jovens sem instrução ou com um a três anos de estudo. Isso ocorre, sobretudo, entre os jovens pobres, para os quais se verificou, em todos os intervalos de anos de estudo (1 a 3; 4 a $7 ; 8$ a $10 ; 11$ a $14 ; 15$ anos ou mais), crescimento na taxa de desocupação: entre esses jovens, 15,5\% é a taxa de desocupação para indivíduos sem instrução e 35,0\% para indivíduos com 15 anos ou mais de estudo. Entre os não pobres, apesar de não se verificar o mesmo crescimento, há variações significativas, como a diferença entre a taxa de desocupação para 1 a 3 anos de estudo, que é de 5,7\%, e para 8 a 10 anos de estudo, que é de 13,1\%.

É nesse ponto que achamos pertinente retomar aquele duplo movimento que apresentamos no início do texto: por um lado, tem-se percebido, tanto objetiva (com altas taxas de abandono no ensino médio) quanto subjetivamente, um fenômeno denominado esvaziamento de significado do espaço escolar; por outro, o forte apelo, com grande respaldo na subjetividade juvenil, à importância da escola para a vida profissional. Diversos olhares para esse fenômeno podem auxiliar-nos a desvendar sua essência, seja recorrendo à ênfase nos processos de construção identitária da juventude, já destacada anteriormente, seja recorrendo às questões de caráter mais estruturante da sociedade.

Apresentamos na seção seguinte alguns breves resultados de duas investigações específicas realizadas em escolas de educação profissional técnica de nível médio do Estado do Paraná. Os dados expostos trazem indícios que consideramos relevantes no que diz respeito a investigações no campo das relações entre juventude e escola, principalmente no que temos destacado até aqui como central: a visão dos sujeitos que constroem o processo escolar.

\section{Identidades juvenis e os sentidos da escola}

As identidades juvenis forjam-se em diferentes tempos e, igualmente, em distintos espaços. 0 jovem constrói-se como sujeito social por meio de interações com grupos dos quais faz parte, ao longo de sua vida. Nesse processo, mais do que ser, ele se configura por um (in) constante ir sendo jovem, de modo que, num jogo de aproximações e distanciamentos a grupos, pessoas, instituições etc., ele constrói sua 
própria identidade, dá sentido à sua vida e, enfim, constrói significados às mais diversas experiências pelas quais passa.

Como as relações sociais dos jovens dão-se em múltiplos espaços, cabe salientar as relações que esses sujeitos estabelecem com a escola e com seu processo de escolarização. Ser jovem e ser aluno não são a mesma coisa, é preciso aceitar a condição de aluno (DAYRELL, 2007). Para os jovens, de acordo com suas pretensões e com os significados que atribuem à experiência escolar, ser aluno adquire uma gradação de importância diferente, indo de uma obrigatoriedade que se deve suportar até a possibilidade de usar a escola como um motor de projeção social posterior. É a partir dessa perspectiva que se empreendeu a análise das pesquisas ora relatadas.

\section{A pesquisa nos colégios agrícolas}

Numa das pesquisas realizadas, o recorte empírico consistiu na análise dos colégios agrícolas paranaenses. Constatou-se, de antemão, uma realidade distinta da normalidade da educação profissional técnica de nível médio ou mesmo do ensino médio regular: no campo pesquisado, a permanência era mais alta, em torno de $80 \%$. Tendo por base esse dado, a pesquisa embrenhou-se em perceber desde os motivos que levaram esses jovens a procurarem o Curso Técnico em Agropecuária Integrado até os significados construídos em sua experiência escolar, passando pelas projeções de futuro profissional e pelas razões para que os sujeitos tenham permanecido e não abandonado a escola.

No primeiro momento da pesquisa de campo, foram realizadas observações sistemáticas das duas instituições agrícolas que servem de campo empírico da investigação. A ideia dessa observação era a de perceber aspectos do cotidiano e da convivência dos alunos na escola. Além disso, com o intuito de melhor especificação do campo de pesquisa, foram analisados documentos da escola, tais como: projeto político-pedagógico; plataforma de turma; regulamentos internos etc. Também foi aplicado questionário a dezesseis alunos concluintes do Curso Técnico em Agropecuária. A intenção desse questionário era a de revelar o perfil socioeconômico da amostragem pesquisada

Por fim, foram realizadas entrevistas com dezesseis alunos concluintes e quatro não concluintes do Curso Técnico em Agropecuária Integrado, bem como com oito docentes e membros das equipes técnico-pedagógicas das instituições analisadas. 0 objetivo dessa entrevista era o de, a partir de roteiros semiestruturados, criar uma espécie de diálogo gravado em que se buscassem elementos de evidências que respondessem ou tentassem responder às questões centrais suscitadas na pesquisa.

Para determinar o recorte do campo empírico, foi realizada pesquisa exploratória estabelecendo quais instituições de ensino serviriam de base para o estudo. 0 critério adotado foi 0 de escolher dois colégios agrícolas, sendo um com a maior taxa de permanência no período pesquisado (2007-2009) (denominado ficticiamente Colégio Gama) e outro (nominado, nesta pesquisa, como Colégio Alfa) com a menor taxa de permanência no mesmo período.

A análise dos dados coligidos mostrou que a maioria dos sujeitos $(71,42 \%)$ atribuiu sua ida àquele colégio e àquele curso à profissionalização esperada. Ou seja, de início, a busca pela escola de nível médio não se deu por uma obrigatoriedade, mas por uma escolha pessoal. Isso, grosso modo, poderia criar uma relação de maior proximidade entre o sujeito e a escola. Ademais, esses mesmos sujeitos têm grandes pretensões profissionais ou de sequência de seus estudos, conforme se percebe nas falas a seguir:

Eu não sei muito bem o que eu quero. Eu queria fazer veterinária, mas, pela área, eu acho que vou fazer agronomia. Agora, se eu não passar na faculdade eu vou procurar um emprego como técnico. (Entrevistado 19 - aluno concluinte do Curso Técnico em Agropecuária Integrado) 
Eu quero fazer vestibular e fazer veterinária. Se eu passar no vestibular e entrar na faculdade, eu vou adiante. Eu quero ter curso superior. Mas, se não der certo, eu quero continuar sendo técnica. (Entrevistado 3 - aluno concluinte do Curso Técnico em Agropecuária Integrado)

De fato, o que se percebeu com a pesquisa é que os Cursos Técnicos em Agropecuária Integrados estão amparados numa estrutura considerada muito boa, com grande quantidade e boa qualidade de profissionais, espaços, materiais etc. Isso propicia, apesar de parcialidades e falhas percebidas, uma boa formação profissional.

Contudo, essa condição apresentada não era satisfatória para responder à questão sobre a alta permanência dos alunos num colégio agrícola. Isso somente se evidenciou quando os alunos foram instados a demonstrar o que a escola significava para eles, qual era o sentido que eles atribuíam à experiência escolar. A totalidade dos alunos atribuiu um significado positivo à escola e à sua passagem por ela, apesar de não deixarem de revelar pontos negativos, como se percebe no seguinte excerto:

Aprender a viver. Ah, sei lá! Aprendi muito aqui dentro. Coisa certa, vi muita coisa errada. Serviu pra ter uma base pra vida daqui pra frente. Eu acho que é ruim, mas dá uma estrutura boa. (Entrevistado 16 - aluno concluinte do Curso Técnico em Agropecuária Integrado)

Ficou evidente também que nem sempre a escola, como instituição, foi a responsável pela criação de tal significado positivo. Este foi, por muitas vezes, forjado nas relações entre os próprios alunos, já que eles levavam para lá quase todas as relações sociais que, em condições normais, deveriam ter fora da escola. Trata-se de uma prática curricular quase sempre oculta, em que os jovens formam-se e forjam-se por si próprios. Esse é, em nossa visão, o elemento central para que se criem as condições de permanência dos alunos na instituição. Assim, a escola foi boa, propiciou boas lembranças, não necessariamente pelo que ensinou dentro de sala de aula, mas pelo que foi capaz de proporcionar neste e em outros ambientes considerados relevantes na visão dos jovens alunos.

Tendo por base os dados analisados, é possível anunciar as seguintes conclusões. Mesmo correndo o risco de ser apenas uma ilusão, os alunos e os professores enxergam grandes chances de um bom futuro profissional, para o egresso do Curso Técnico em Agropecuária Integrado, o que se mostrou diretamente relacionado com as razões de permanência. Essa aura é construída por dois fatores: possibilidades eminentes de empregabilidade e grandes chances de aprofundar os estudos num curso superior da área. Sobre o primeiro fator, salienta-se que, mesmo com a mecanização da agricultura e da pecuária, apesar da constante diminuição de postos de trabalho no setor primário (POCHMANN, 2007), ainda existe uma grande necessidade de mão de obra nessa área, principalmente devido à expansão das fronteiras agrícolas ainda em processo no Brasil. Desse modo, os cursos técnicos em agropecuária acabam sendo inseridos numa estrutura produtiva que requer profissionais com essa formação. 0 segundo fator, que diz respeito às possibilidades de prosseguir os estudos, formando-se em nível superior, talvez se deva ao fato de se estar numa escola integral, bem estruturada, e de se ter contato com profissionais das áreas da agronomia, da veterinária ou da zootecnia. Isso poderia alimentar um sonho de novas possibilidades de estudo e de uma profissionalização mais estruturada.

Além disso, a pesquisa evidenciou que as escolas têm recebido uma visão otimista por parte dos sujeitos jovens que, lá, são alunos. Isso não é resultado, necessariamente, de uma ação consciente da escola, do colégio agrícola, ou seja, não se pode afirmar que os pontos positivos são oriundos da instituição em sua formalidade, ou mesmo das pessoas que 
a comandam. Cria-se nos colégios agrícolas, contudo, um espaço-tempo em que se pode, por exemplo, conciliar amizades com qualidade de formação, mesmo quando não se goste de alguns aspectos, como a direção, a estrutura física etc. Dito de outra forma, o significado que a escola ou o colégio agrícola assume para os sujeitos que ali estudam é positivo. Assim, os sentidos que a experiência escolar lhes permite criar são igualmente positivos.

Cada sujeito projeta um sentido diferente para sua relação com a escola, atribuindo-lhe, portanto, significados próprios. São exemplos disso falas como:

Aprendi também que tem coisas que tem regras. Ah, foi uma escola da vida, né, cara. Nunca mais eu vou esquecer dessa escola (Entrevistado 7 - aluno concluinte do Colégio Alfa);

ou então declarações que mostram a importância da escola, mesmo que ela tenha apresentado problemas:

Aprender a viver. Ah, sei lá! Aprendi muito aqui dentro. Coisa certa, vi muita coisa errada. Serviu pra ter uma base pra vida daqui pra frente. Eu acho que é ruim, mas dá uma estrutura boa. (Entrevistado 16 aluno concluinte do Colégio Gama)

Cada um desses discursos deve ser

compreendido como [resultado de] um conjunto de experiências - integrado e fracionado - que é vivido e sofrido por indivíduos e grupos em situações e contextos específicos. (GIROUX, 1987, p. 86)

Contudo, a análise feita remete ao fato de que, no conjunto das falas, percebe-se claramente uma ausência de elementos negativos. Todos os alunos de ambas as escolas veem nelas algo que lhes foi importante, que lhes teve um significado positivo. Isso, num momento em que se vive, no mínimo, um deslocamento de sentido e uma perda de significado das escolas, especialmente as de nível médio, é eloquente o suficiente para se afirmar que, nos casos dos colégios agrícolas, ainda se encontra razão para o aluno estar lá.

\section{A pesquisa na área de tecnologias}

A outra pesquisa desenvolvida dedicou-se a analisar uma gama específica de cursos de educação profissional técnica de nível médio ofertados na modalidade integrado ligados à área de tecnologia ou com relação direta com a indústria. 0 principal elemento que caracteriza tais cursos é o fato de eles proporcionarem uma formação que possui relação muito intima com dispositivos e aparatos tecnológicos - utilizando-se tanto a base eletromecânica convencional, quanto processos que se apropriam da microeletrônica e da informática para aplicação ao setor produtivo. ${ }^{3}$ Os cursos selecionados pelo recorte analítico da pesquisa são Eletromecânica, Eletrônica e Edificações, analisados em um Centro Estadual de Educação Profissional do Paraná. A realidade desses cursos é, em certo sentido, oposta à analisada na pesquisa anterior: são cursos que apresentam, ao mesmo tempo, alta procura e elevado abandono. Configuram-se aí um aparente paradoxo e uma realidade fenomênica contraditória, o que nos motivou a debruçarmo-nos sobre tais cursos, procurando explicar, a partir da investigação do ponto de vista do jovem que os procura e da construção identitária dessa parcela da juventude, a essência e os verdadeiros fatores que configuram tal quadro. Concluímos, pois, conforme mostramos nas linhas seguintes e contrariamente ao que a análise superficial ou meramente descritiva força-nos a enxergar, que a alta procura está intimamente relacionada ao alto abandono.

3 - 0 Catálogo Nacional de Cursos Técnicos (BRASIL, 2008) engloba os cursos que foram submetidos à nossa análise em três eixos: Controle $e$ Processos Industriais, Infraestrutura e Produção Industrial. Os três eixos totalizam cinquenta cursos ofertados em todo o país. 
Para chegar a essa conclusão, entrevistamos professores, egressos dos cursos e jovens que abandonaram (nesses casos, trata-se de um abandono do curso e não necessariamente da escola, pois verificamos que a imensa maioria desses jovens migrou para o ensino médio regular). Além disso, realizamos grupos focais com alunos de $1^{\circ}$ e $4^{\circ}$ anos. Os sujeitos da pesquisa totalizaram uma amostra de 81 participantes.

A coleta dos dados para interpretação da realidade investigada foi feita a partir do ponto de vista dos sujeitos que constroem o espaço escolar e o campo de atuação profissional específico: alunos, egressos e professores. Para tanto, iniciamos nosso contato com a empiria realizando uma prévia imersão na escola ao longo de duas semanas, momento em que foram feitos registros de observação de campo. Já para a coleta dos dados propriamente dita, realizada logo após esse período inicial, utilizamos a metodologia de grupos focais com 35 alunos matriculados, divididos em seis grupos, três com alunos de $1^{\circ}$ ano e três com alunos de $4^{\circ}$ anos. Além disso, fizemos entrevistas individuais com dezoito alunos que abandonaram os cursos, vinte egressos e oito professores, totalizando 81 sujeitos envolvidos na pesquisa.

Em primeiro lugar, é necessário expor nossas conclusões sobre aquilo que diz respeito ao que tem levado esses jovens a procurar a escola, especificamente a educação profissional técnica de nível médio nos cursos da área de tecnologia. Evidenciamos, pois, três motivos principais que fazem com que os índices de procura nos cursos sejam bastante altos se comparados com outros cursos da mesma modalidade ou com o ensino médio regular: a influência da família; a influência de discursos ideológicos como mercado aquecido, falta de profissionais qualificados, garantia de altos salários; e a visão do jovem sobre tecnologia.

Por exemplo, quando questionados a respeito do que acham sobre o mercado de trabalho na área dos cursos que escolheram, houve praticamente consenso entre alunos do $1^{\circ}$ ano em afirmar que há um grande núme- ro de vagas e que o mercado está em plena expansão, discurso reforçado pelo panorama de desenvolvimentismo que vive a economia brasileira atualmente.

Dizem que é uma das áreas mais concorridas, principalmente agora que tem muito terremoto essas coisas, eles pesquisam mais engenheiros, eles sempre estão querendo renovar as estruturas nas cidades, então é uma área bastante ampla. (Grupo focal A)

Pelo que meu pai me fala e me mostra, assim, tem bastante vaga. (Grupo focal B)

\begin{abstract}
Ah, tá muito bom. Comparado aos outros, acho que é a área mais ampla. Qualquer empresa que você vai, eles tão procurando alguém. (Grupo focal D)
\end{abstract}

A ênfase na falta de mão de obra qualificada e na facilidade em encontrar emprego também é uma constante no discurso dos professores. Isso fica evidente tanto em constatações dos jovens quanto em falas dos próprios docentes:

Entrevistador: Como é o mercado de trabalho nessa área?

Professor: Tá bombando. Eletromecânica e eletrônica bomba! É extremamente emergente, né? Hoje o que mais se busca é mão de obra qualificada nesse mercado de eletromecânica e... construção civil também, que eu já fui professor aqui. Química. A Petrobrás tem inclusive, aí, nos próximos 20 anos vai precisar de quase 200 mil técnicos e engenheiros, né? Na área de mecânica, eletromecânica, eletrônica, química, meio ambiente, construção civil. E ela vai ter que, pelo que a gente tem lido aí, importar essa mão de obra, né? Então, mercado de trabalho pra o que existe aqui dentro desse colégio... é realmente muito promissor. (Entrevista com professor dos cursos de Edificações, Eletrônica e Eletromecânica, em disciplina básica) 
Além disso, constatamos que essa visão também é construída nas relações familiares, pois a família apropria-se desses discursos e acaba por impulsionar o jovem a matricular-se nos cursos. 0 panorama de inserção no mundo do trabalho que verificamos entre os egressos do curso desmistifica esse fetiche contido na visão dos jovens: dos vinte egressos entrevistados, apenas cinco atuam como técnicos; os outros quinze assumem ocupações como operários (soldador, operador de máquina, montador), aprendizes (de eletricista, de pedreiro e de mecânica), estagiários ${ }^{4}$ ou até estão desempregados, o que ocorre com três entrevistados. Ou seja, a ênfase no discurso do mercado aquecido e da falta de profissionais qualificados apenas legitima a precarização do trabalho própria desse período de acumulação. De fato, faltam técnicos para o setor produtivo; porém, a inserção desses técnicos no mundo do trabalho dá-se de modo a ocupar funções que não condizem com a formação que receberam.

Finalmente, passamos a comentar a respeito das possíveis causas para o abandono da escola. Identificamos diversos fatores relatados pelos alunos e os dividimos em cinco grupos. Desenvolvemos mais detalhadamente aqui apenas o grupo majoritário, no qual se encaixa mais da metade das causas de abandono citadas e que corresponde àquelas questões que possuem como raiz central a relação com os próprios motivos que levam à alta procura. Nesse grupo, as principais questões apontadas foram: preferência pelo ensino médio regular, falta de gosto pelo curso e dificuldade nas disciplinas.

Construímos a primeira categorização a partir de diversos argumentos. Por exemplo, há alunos que pretendem fazer vestibular e entrar o mais rápido possível na universidade. Para estes, os quatro anos do curso técnico seriam um empecilho. De qualquer forma, o que fica claro nos depoimentos dos alunos que afirmaram ter preferência pelo ensino médio regular é que não

4 - Há casos de jovens que concluem os cursos e, por razões de diminuição de custos alegadas abertamente pelas empresas, continuam trabalhando como estagiários e já executando o serviço de técnicos. é, precisamente, a preferência por essa modalidade de ensino que os fez abandonar, mas, ao contrário, a não preferência pelo ensino técnico, o qual, quando estavam no ensino fundamental, constituía-se como uma grande expectativa para eles e, principalmente, para suas famílias. Ao não encontrarem atrativos no curso técnico pelo contrário, ao sentirem dificuldades de adaptação e perceberem que os quatro anos de curso podem, talvez, trazer as mesmas implicações que um curso regular de três anos -, os alunos os abandonam em direção ao ensino médio regular, a fim de concluir essa etapa da vida escolar em menos tempo. E são exatamente esses condicionantes que levam os alunos a abandonar alegando as outras duas questões que ressaltamos nesse grupo: falta de gosto pelo curso ou dificuldade nas disciplinas. Em relação à falta de gosto, as falas a seguir, de um jovem que abandonou o curso e de um aluno do $1^{\circ}$ ano que alegou já ter pensado várias vezes em abandonar, respectivamente, são elucidativas:

Foi assim: é que na verdade o curso não era bem o que eu queria, sabe? Foi uma coisa mais precipitada assim. Entende? Eu não tinha me especializado muito no que eu queria fazer, num tinha estudado muito sobre o curso, então foi uma coisa que só aconteceu e quando eu vi, eu já tava fazendo o curso. Então, assim, foi meio que precipitado e quando eu vi num era realmente o que eu queria fazer. (Aluno que abandonou o curso de Eletromecânica no $1^{\circ}$ ano, em 2010)

Agora que eu to começando a me interessar por essa área. Mas, na verdade, no começo, na hora que começaram a falar, assim, o que a gente ia fazer, eu já pensei "Nossa, onde é que eu fui me meter, né, um lugar, tipo, totalmente estranho?”. (Grupo focal A)

Ou seja, a falta de clareza a respeito dos cursos é o principal fator da maioria dos casos de abandono. Os outros grupos de causas do 
abandono, que apareceram em número menor de vezes, englobam fatores como a incompatibilidade entre os horários das aulas e o horário de trabalho ou entre o local da escola e o local de moradia; a transferência para outra escola técnica na qual procuravam vaga prioritariamente; e experiências com a escola caracterizadas como fracasso escolar, o que compreende desde a dificuldade de aprender até a reprovação em determinada(s) disciplina(s).

Outra ordem de razões para o abandono do curso que se articula às demais diz respeito a uma visão essencialmente positiva, idealista e fetichizada sobre a tecnologia. Esse elemento sofre influência direta das visões apresentadas pelos próprios professores - e, obviamente, expostas em sala de aula - e da vivência que esses alunos já adquiriram pela vida em sociedade ou no mundo do trabalho. Foram evidenciadas diversas dimensões dessa visão fetichizada da tecnologia e do quanto ela é responsável pela elevada procura e também pelo alto abandono dos cursos.

Constatamos que as visões de jovens e professores sobre a tecnologia, construídas no seio das relações sociais, são fatores determinantes para o desenvolvimento dos sentidos e significados desses jovens a respeito da área de atuação técnica que escolheram. Os consensos em relação ao alto número de vagas no mercado de trabalho e a suposição de garantia de um salário que garantiria uma vida sem dificuldades financeiras no trabalho levaram-nos à conclusão de que os elementos que explicam a alta procura nos cursos são exatamente as visões superficiais a respeito dessa área de atuação.

Ao se depararem com outra realidade e ao amadurecerem seus desejos e anseios em relação ao futuro profissional, os jovens acabam por se questionarem a respeito do gosto pelo curso e abandonam a escola de ensino técnico. Ou seja, é a própria falta de clareza sobre o curso no momento da escolha, construída no âmago de uma visão fetichizada a respeito da tecnologia e da profissão, que se coloca como fator determinante para o abandono, de modo que as causas do abandono são encontradas nos próprios motivos que configuram a alta procura pelos cursos.

\section{Considerações finais}

Ao início das pesquisas, supôs-se que os jovens que abandonam a escola, em grande medida, fazem-no por não considerá-la representativa, de tal modo que ela já não tivesse mais sentido ou significado para eles, ou que, ao menos, esse sentido estivesse deslocado de uma esfera mais tradicional, em que estar na escola pudesse significar algo importante, seja pela aquisição de conhecimentos, seja por uma possível promoção social. 0 que se pode depreender, a partir das duas pesquisas realizadas, confirma em parte essa hipótese. Verifica-se mais o deslocamento do significado do que a perda de sentido da escola.

Busca-se a escola por vários motivos. No caso da escola de educação profissional técnica de nível médio na área de tecnologia, tenta-se encontrar uma formação de qualidade superior, ou mesmo a profissionalização em áreas que, em nossa sociedade, representam certo status ou a garantia de empregabilidade. Contudo, ao se frequentar a escola, as ilusões iniciais dissolvem-se, problemas para acompanhar a realização do curso evidenciam-se, a relação entre a escola e o jovem mantém-se distanciada e, assim, não se veem mais motivos para permanecer na escola.

Outra realidade enxergada na pesquisa com os colégios agrícolas mostrou que, mesmo a escola não tendo a intencionalidade de criar uma significação positiva junto aos alunos, isso acontece devido ao grau de experiências positivas que esses jovens podem viver enquanto estão matriculados numa instituição integral, interna, bem estruturada. Esse dado, mais do que uma consideração de resposta à hipótese inicial, oferece-nos um indicativo político: especialmente na última década, com políticas públicas mais sérias para a educação profissional, foram criadas instituições que são ainda capazes de ser, de representar algo importante na vida dos sujeitos 
que nelas estudam. 0 problema está no fato de essas instituições, como os colégios agrícolas, serem exceções. Apesar disso, mesmo em tais escolas, o sentido do que é ser jovem ainda carece de melhor entendimento; nesse sentido, a partir de uma compreensão mais aprofundada, talvez se possa tratar os jovens alunos como coartífices do processo educativo e não somente como alunos, figuras passageiras na instituição.

Para finalizar, indicamos a urgência de que se ressignifique o espaço-tempo das escolas de ensino médio, favorecendo o sentido da escola como local privilegiado, ainda que não exclusivo, no qual a identidade juvenil se constrói. Para isso, entendemos como necessário que se insiram, nos cursos de formação de professores, estudos sobre a juventude e suas relações com a escola, pois isso levaria à consolidação de relações menos estereotipadas ou preconceituosas; com a mesma finalidade, urgem experiências curriculares que possibilitem uma experiência escolar plena de significação, que ultrapassem as organizações disciplinares formais e permitam, ao lado do aprendizado da ciência, da ética e da estética, ressignificados, a vivência de experiências próprias do universo juvenil, com suas múltiplas linguagens e formas de ver e viver o mundo.

Duas observações são ainda necessárias para finalizarmos nossas considerações finais. Em primeiro lugar, é necessário ter em mente que, ratificando nossa concepção a respeito das mediações existentes entre as relações sociais e os fenômenos escolares e considerando a cultura escolar e a própria organização da escola como processos fundamentais a serem levados em conta nas pesquisas sobre o ensino médio e a educa- ção profissional, não encontramos nenhum indício de que a dificuldade de conciliar trabalho e estudo seja a causa central do abandono escolar. Ou seja, ao contrário do que parece ao senso comum, mesmo com condições de se sustentar materialmente (a maioria dos jovens que entrevistamos não necessita trabalhar durante o curso para se manter financeiramente), há questões estruturais mediadas pela própria organização da escola que levam o jovem a abandonar.

Em segundo lugar, chamamos a atenção para a necessidade de se questionar qual é a expansão do ensino técnico que está em jogo no Brasil, quando, na verdade, o que é levado a cabo pelo poder público é uma expansão que não se propõe a alterar a essência estrutural da educação técnica, mas, sob o discurso da democratização, simplesmente ampliar o acesso a esse nível de ensino em sintonia com as demandas do mercado e do desenvolvimento, sem uma problematização mais profunda acerca de questões que são centrais para o processo de educação formal, como o currículo, as visões e os anseios dos alunos, a cultura escolar e a gestão da escola pública. Basta lembrar, por exemplo, que estamos falando de processos educativos regulamentados por um currículo que procura integrar educação propedêutica e ensino profissional e que não dá conta de apresentar a tecnologia em sua construção histórica mediada por relações sociais. A conjuntura econômica coloca a expansão na ordem do dia e os avanços nesse sentido são fundamentais. Porém, os níveis alarmantes de abandono se impõem como uma realidade que precisa ser transformada para que a expansão da educação profissional ocorra com qualidade social. 


\section{Referências}

ABRAMO, Helena Wendel. Condição juvenil no Brasil contemporâneo. In: ABRAMO, Helena Wendel; BRANCO, Pedro Paulo Martoni (Orgs.). Retratos da juventude brasileira: análises de uma pesquisa nacional. São Paulo: Fundação Perseu Abramo, 2008. p. 37-72.

ABRAMOVAY, Miriam; CASTRO, Mary Garcia. Ensino médio: múltiplas vozes. Brasília: UNESCO/MEC, 2003.

BOURDIEU, Pierre. A "juventude" é apenas uma palavra. In: Questões de sociologia. Rio de Janeiro: Marco Zero, 1983. p. 112-121.

BRASIL. Ministério da Educação. Instituto Nacional de Estudos e Pesquisas Educacionais Anísio Teixeira. Sinopse estatística da educação básica, 2006. Brasília, DF, 2006. Disponível em: <http://portal.inep.gov.br/basica-censo-escolar-sinopse-sinopse> . Acesso em: 6 jun. 2011.

Ministério da Educação. Catálogo nacional de cursos técnicos, 2008. Brasília, DF, 2008. Disponível em: <http:// catalogonct.mec.gov.br/>. Acesso em: 27 abr. 2012.

Ministério da Educação. Instituto Nacional de Estudos e Pesquisas Educacionais Anísio Teixeira. Sinopse Estatística da Educação Básica, 2009. Brasília, DF, 2009. Disponível em: <http://portal.inep.gov.br/basica-censo-escolar-sinopse-sinopse> . Acesso em: 6 jun. 2011.

COSTA, Marcio da; KOSLINSKI, Mariane Campelo. Entre o mérito e a sorte: escola, presente e futuro na visão de estudantes do ensino fundamental do Rio de Janeiro. Revista Brasileira de Educação, Rio de Janeiro, v. 11, n. 31, p. 133-154, jan./abr. 2006.

DAYRELL, Juarez. 0 jovem como sujeito social. Revista Brasileira de Educação, Campinas, n. 24, p. 40-52, set./dez. 2003.

. A escola "faz" as juventudes? Reflexões em torno da socialização juvenil. Educação e Sociedade [online], v. 28, n. 100, p. 1105-1128, 2007. Disponível em <http://www.scielo.br/pdf/es/v28n100/a2228100.pdf>. Acesso em: 10 jun. 2011.

. Juventude e escolarização: os sentidos do ensino médio. In: BRASIL. Ministério da Educação. Salto Para o Futuro. ano XIX, boletim 18. Brasília, DF: MEC, nov. 2009.

DUBET, François. Quando o sociólogo quer saber o que é ser professor. Entrevista concedida a Angelina Teixeira Peralva e Marilia Pontes Sposito. Revista Brasileira de Educação, Rio de Janeiro, n. 5 e 6, p. 222-231, 1997.

GIROUX, Henry. Escola crítica e política cultural. Tradução de Dagmar M. L. Zibas. São Paulo: Cortez; Autores Associados, 1987. (Polêmicas do nosso tempo; 20)

HARVEY, David. Condição pós-moderna: uma pesquisa sobre as origens da mudança cultural. 20. ed. São Paulo: Loyola, 2010.

IBGE (INSTITUTO BRASILEIRO DE GEOGRAFIA E ESTATÍSTICA). Pesquisa nacional por amostra de domicílios (PNAD): síntese de indicadores, 2009. Rio de Janeiro: IBGE, 2010.

POCHMANN, Marcio. Situação do jovem no mercado de trabalho no Brasil: um balanço dos últimos 10 anos. São Paulo: mimeo, 2007.

RIBEIRO, Rosana; NEDER, Henrique D. Juventude(s): desocupação, pobreza e escolaridade. Nova Economia, Belo Horizonte, n. 19, p. 465-506, 2009.

SILVA, Mônica Ribeiro. Currículo e competências: a formação administrada. São Paulo: Cortez, 2008.

SIMÕES, Carlos Artexes. Políticas públicas do ensino médio: realidade e desafios. In: FERREIRA, Cristina Araripe (Org.). Juventude e iniciação científica: políticas públicas para o ensino médio. Rio de Janeiro: EPSJV; UFRJ, 2010. p. 135-142. 
SPOSITO, Marilia Pontes. Algumas reflexões e muitas indagaç̃es sobre as relações entre juventude e escola no Brasil. In: ABRAMO, Helena Wendel; BRANCO, Pedro Paulo Martoni (Orgs.). Retratos da juventude brasileira: análises de uma pesquisa nacional. São Paulo: Editora Fundação Perseu Abramo, 2008. p. 87-128.

Recebido em: 26.04.2012

Aprovado em: 18.09.2012

Monica Ribeiro da Silva é doutora em Educação e professora no Departamento de Planejamento e Administração Escolar da Universidade Federal do Paraná (UFPR).

Lucas Barbosa Pelissari é mestre em Educação e professor no Centro de Engenharia e Ciências Exatas da Universidade do Oeste do Paraná (UNIOESTE).

Allan Andrei Steimbach é mestre em Educação pela Universidade Federal do Paraná (UFPR), diretor auxiliar e professor do Curso de Formação de Docentes do Colégio Estadual Mário de Andrade, de Francisco Beltrão. 
